\title{
Developing a theory-based multimedia intervention for schools to improve young people's asthma: my asthma in school (MAIS)
}

Gioia Mosler ${ }^{1 *}$ (D) Katherine Harris ${ }^{1}$, Jonathan Grigg ${ }^{1}$ and Liz Steed ${ }^{2}$

\begin{abstract}
Background: Asthma control in adolescents is low with half of the young people in a London study identified as having suboptimal control when measured using the Asthma Control Test. Control of asthma symptoms can be improved by addressing barriers to good self-management, such as poor understanding of asthma and adherence to medication. The aim of this study was therefore to develop the My Asthma in School (MAIS) intervention for the improvement of asthma control and self-management in adolescents and to test its initial feasibility. The intervention intended to combine a strong focus on theory with a design specifically aimed to engage adolescents.

Methods: The intervention development was based on previous qualitative and quantitative findings, and on guidelines from the Medical Research Council for the development of complex interventions. The COM-B (Capability, Opportunity, Motivation-Behaviour) model was applied to inform the design of intervention elements. Behavioural targets were identified from existing barriers to good asthma self-management and were then used to guide the development of engaging intervention elements, which were described using the Behavioural Change Technique (BCT) Taxonomy version 1. Adolescents were involved throughout this process. The MAIS intervention was tested in a feasibility phase in London secondary schools with adolescents aged between 11 and 13 .

Results: The complex school-based MAIS intervention comprised a first school visit from a theatre group, who conducted a workshop with all year 7-8 students and addressed peer understanding and attitudes to asthma. The second visit included four self-management workshops for adolescents with asthma, including games, short-films and role play activities. Forty different types of techniques to change behaviour were applied, totalling 163 instances of BCT use across intervention elements, addressing all areas of capability, opportunity and motivation. In this initial feasibility study, 1814 adolescents with and without asthma from nine schools received the theatre intervention visit; 23 adolescents with asthma from one of the schools attended the workshop visit. The intervention was found acceptable and engaging, and $91.4 \%$ of participants agreed that the workshops changed how they think or feel about asthma.

(Continued on next page)
\end{abstract}

\footnotetext{
* Correspondence: g.mosler@qmul.ac.uk

${ }^{1}$ Centre for Genomics and Child Health, Blizard Institute, Barts and the

London School of Medicine and Dentistry, Queen Mary University of London,

4 Newark St, London E1 2AT, UK

Full list of author information is available at the end of the article
}

C C The Author(s). 2020 Open Access This article is licensed under a Creative Commons Attribution 4.0 International License, which permits use, sharing, adaptation, distribution and reproduction in any medium or format, as long as you give appropriate credit to the original author(s) and the source, provide a link to the Creative Commons licence, and indicate if changes were made. The images or other third party material in this article are included in the article's Creative Commons licence, unless indicated otherwise in a credit line to the material. If material is not included in the article's Creative Commons licence and your intended use is not permitted by statutory regulation or exceeds the permitted use, you will need to obtain permission directly from the copyright holder. To view a copy of this licence, visit http://creativecommons.org/licenses/by/4.0/. The Creative Commons Public Domain Dedication waiver (http://creativecommons.org/publicdomain/zero/1.0/) applies to the data made available in this article, unless otherwise stated in a credit line to the data. 
(Continued from previous page)

Conclusion: This study demonstrates development and initial feasibility of a complex theory-based intervention, and how it can combine engaging media and interactive elements, to achieve a multi-directional approach to behavioural change. However more work is needed to assess the feasibility of trial processes, including recruitment and delivery format of the workshops.

Keywords: Asthma, Self-management, Behavioural change, Adolescents, Young people, Intervention, Multimedia, Theory-based, Engagement, Gamification

\section{Key messages regarding feasibility}

- What uncertainties about feasibility existed?

There was no information on the acceptability of the developed MAIS intervention and the feasibility of its delivery in the school context.

- What are the key findings about feasibility?

The delivery of the MAIS intervention is feasible within the school context, and both elements of the intervention received very positive feedback from participating children and young people.

- What are the implications of these results for the design of the main study?

The results of this feasibility study can inform the design and development of a randomised controlled trial.

\section{Background}

Asthma is the most common chronic condition in children and young people in the UK [1]. For the majority of asthma patients, medications have the potential to control symptoms well [1]. Yet, there is evidence in the UK that almost half (49.6\%) of young people (between 12 and 18 years of age) has suboptimal asthma control when assessed by the Asthma Control Test (ACT) [2]. Poor control frequently leads to unscheduled medical care with $30 \%$ of young people reporting an unplanned visit to a general practitioner (GP) in the past month [2]. UK also has a higher rate of asthma-related deaths compared to other European countries [3, 4]. Results from the school-based asthma project (SAP) [2] reported a lack of understanding of symptom severity. Of the young people identified with suboptimal asthma control, $42.4 \%$ judged their asthma to be either 'well' or 'completely controlled' [2].

Insights into why many adolescents do not have good asthma control are provided by qualitative findings from the SAP study. For example, reported barriers to successful self-management included forgetfulness, a lack of understanding of asthma and prescribed medication, as well as a fear of negative social interactions, such as teasing or bullying. These findings are similar to other studies which have reported forgetfulness as a barrier to adherence to asthma medication $[5,6]$ and desire to fit social expectations [5] as important influences on adherence and control.

Adolescence is a time of great physical, social and emotional change, resulting in age-specific needs. Adolescents with asthma therefore have different needs in relation to their chronic condition compared to smaller children or adults [7]. During adolescence, patients transition from predominantly parental management of their asthma to individual self-management. At this time, young people might question or change previously established routines, as they start to take more independent decisions about their health. Adolescence may therefore provide the opportunity to set up optimal behavioural standards for a young person which have the potential to last into adulthood [8].

Reviews of interventions in young people suggests that schools are effective locations to deliver asthma selfmanagement interventions [9-13] which can improve outcomes, such as medication use and health-related quality of life, and can reach individuals who might not regularly access healthcare.

The need for a novel, theoretically informed intervention to improve young people's attitudes and understanding of asthma, and subsequent self-management and symptom control, was identified. The My Asthma in School (MAIS) intervention was designed to achieve this. The intervention targeted young people aged 11-13 years, in order to embed the behavioural standards early in adolescence. This paper describes (i) the development of the MAIS in line with MRC principles and (ii) initial feasibility and acceptability testing of the intervention.

\section{Methods}

\section{Intervention development of the my asthma in school} intervention

The aim of the My Asthma in School (MAIS) intervention was to improve asthma control and self-management in adolescents. An overview of the intervention development 
is presented in Fig. 1 and described using the TiDieR framework (Supplement 1) and a logic model of the intervention (Supplement 2).

Intervention development followed MRC complex intervention guidance which suggests that complex interventions should be (1) evidence based and (2) theory based. The guidelines also state the importance of (3) involving of experts. Medical and behaviour change specialists were consulted throughout the development. In order to maximise engagement and commitment of adolescent patients, practical educational expertise was also included. (4) The involvement of patients and their community was central throughout all development steps. As part of this development phase, further feasibility work is recommended before formal evaluation in a trial context.

\section{Evidence base}

Systematic reviews suggest the need to improve selfmanagement of asthma in the adolescent population [9-13]. However, it is important to understand the specific barriers to self-management and delineate separate behaviours within self-management. The SAP study [2] used qualitative methodology to understand what self-management meant to adolescents and where they were having difficulties. This directly informed the identification of target behaviours and specific areas to focus the intervention.

\section{Theory base}

The approach used for MAIS was the behaviour change wheel, with a focus on the theoretical domain framework and the COM-B model (Capability, Opportunity, Motivation-Behaviour) at its centre [14]. An important first step is to understand the behaviour (poor selfmanagement) and break it down into its component target behaviours, here termed sub-behaviours. Based on previous literature $[1,15-17]$, six sub-behaviours to asthma self-management were identified and can broadly be described as:

A. Adherence to medication: This can be considered as whether one follows the prescribed medication regimen, but is interpreted here as encompassing not only the taking of medication but also factors influencing this, such as recognition of symptoms and understanding how common asthma medicines work.

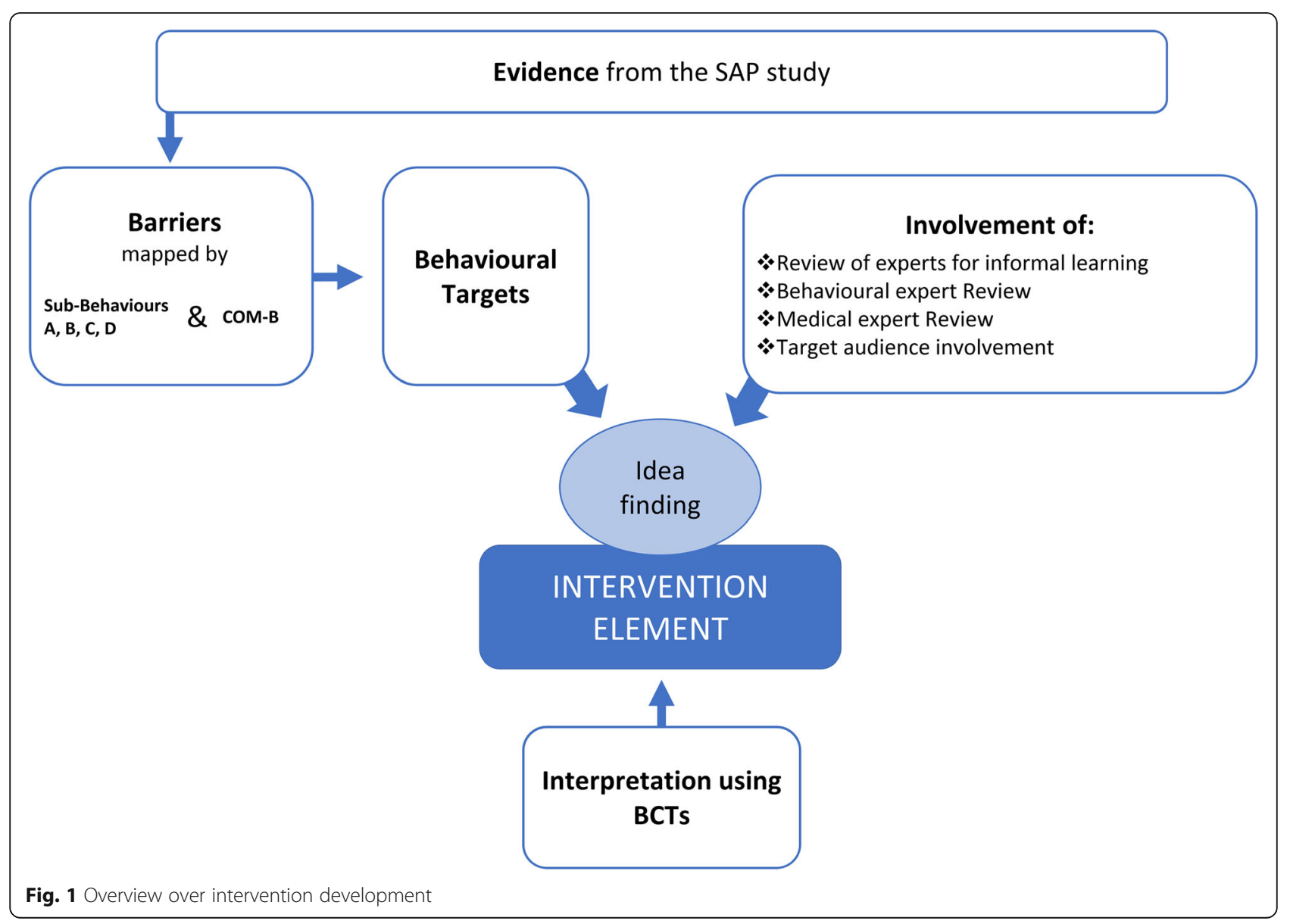


B. Inhaler technique: Most young people with asthma regularly use an inhaler to administer their asthma medication. According to Asthma UK, up to $1 / 3$ of people with asthma use their inhaler incorrectly and therefore get less of their required medication [18]. Spacers that can be attached to many regularly prescribed inhalers increase the intake of inhaled medication and can reduce the side effects of medication [19]. Spacers are however often considered by adolescents to be childish and are therefore often not used as prescribed [19-21].

C. Trigger avoidance: Asthma symptoms get worse when exposed to certain triggers. Triggers vary individually but can include pet hair or air pollution. Exposure to many different triggers can be avoided or reduced, and recognition of personal triggers and possible ways to avoid exposure are a crucial part of asthma management.

D. Emergency response: Knowing relevant steps to take during an asthma exacerbation is crucial for asthma sufferers. It was indicated by several participants of the SAP focus groups that they did not know what to do in an asthma emergency, and they could not advise others either.

E. Effective communication with healthcare professionals: It is essential for a patient to communicate quickly and effectively during a consultation with a healthcare professional, in order to receive the best possible care [1].

F. Empowerment to self-manage: In order for an individual to carry out a behaviour, they must feel they have knowledge, sense of control and confidence to carry out this behaviour. This is known as empowerment.

\section{Setting behavioural targets and mapping behavioural barriers}

Within each sub-behaviour, the identified barriers from previous qualitative and quantitative data collections were mapped by two authors, one an expert in behaviour change. We used the COM-B model to categorise whether the barrier reflected limitations in an individual's physical and/or psychological capability, their physical and/or social opportunity, and their automatic and/ or reflective motivation. This allowed us to consider for each sub-behaviour which areas the intervention should target. As a next step, we then defined new targets to support self-management. Table 1 shows a summary of this work.

For five of the six sub-behaviours, psychological capability emerged to be one of the most commonly mapped COM categories. For example, barriers to subbehaviour: (A) Adherence to medication, such as 'Forgetfulness' and for sub-behaviour (D) Emergency response, the 'Lack of knowledge about how to respond to an emergency'. Many barriers were also mapped to the COM category of social opportunity across different sub-behaviours. Examples include barriers to subbehaviour (C) Trigger Avoidance: 'Lack of social support in reducing effect of triggers', or barriers to (F) Empowerment to self-manage, such as a 'Perceived lack of understanding by non-asthmatics'. These findings directly informed the focus of the developed intervention.

\section{Developing the intervention format and elements Intervention format}

As psychological capability was a key target area for the intervention, including improvements on knowledge and understanding of asthma; workshops for young people with asthma aged 11 to 13, supported with resources such as apps and information booklets, were felt to be an appropriate form of delivery. Workshops have been used successfully by similar interventions and allow for tailoring and engagement of participants [9]. They furthermore are highly suitable to the school environment. Due to the risk of a high dropout rate from repeated visits, based on experience with previous work in schools, a 1-day workshop with four parts was developed.

The evidence (shown in Table 1) suggested that social opportunity, i.e. involving the peer group of young people with asthma, was another important target area to support self-management. Theatre workshops are a medium which has previously been proven effective in addressing attitudes in young people [22] and are therefore considered a novel intervention to target the peer environment. They can also be delivered to large numbers of individuals and can be accommodated with relative ease in the school context.

\section{Developing engaging and effective intervention elements}

To ensure engaging and appropriate workshop content, iterative input was gained from:

i) Over 50 young people with asthma between 10 and 16 years of age during over 40 visits to the waiting rooms of two paediatric asthma clinics in London hospitals. A further eight focus groups in schools were used to receive input on intervention elements.

ii) An outreach and learning team of experts with dual backgrounds in research and research communication who worked directly with the university's science education centre, Centre of the Cell. This is a science centre specialising in the development and delivery of engaging workshops, shows and video games with a focus on medical topics for young people [23]. Ideas about how to 


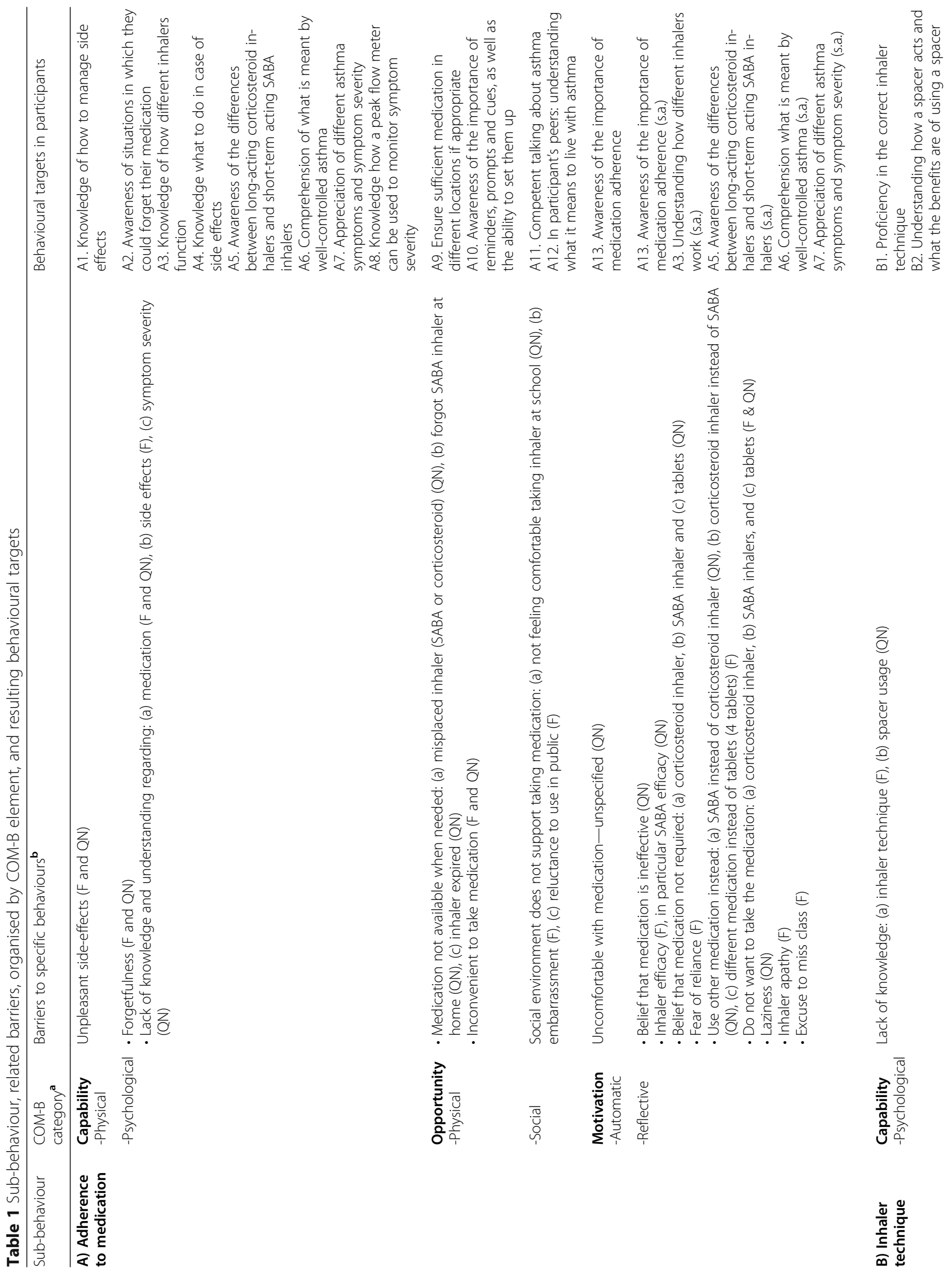




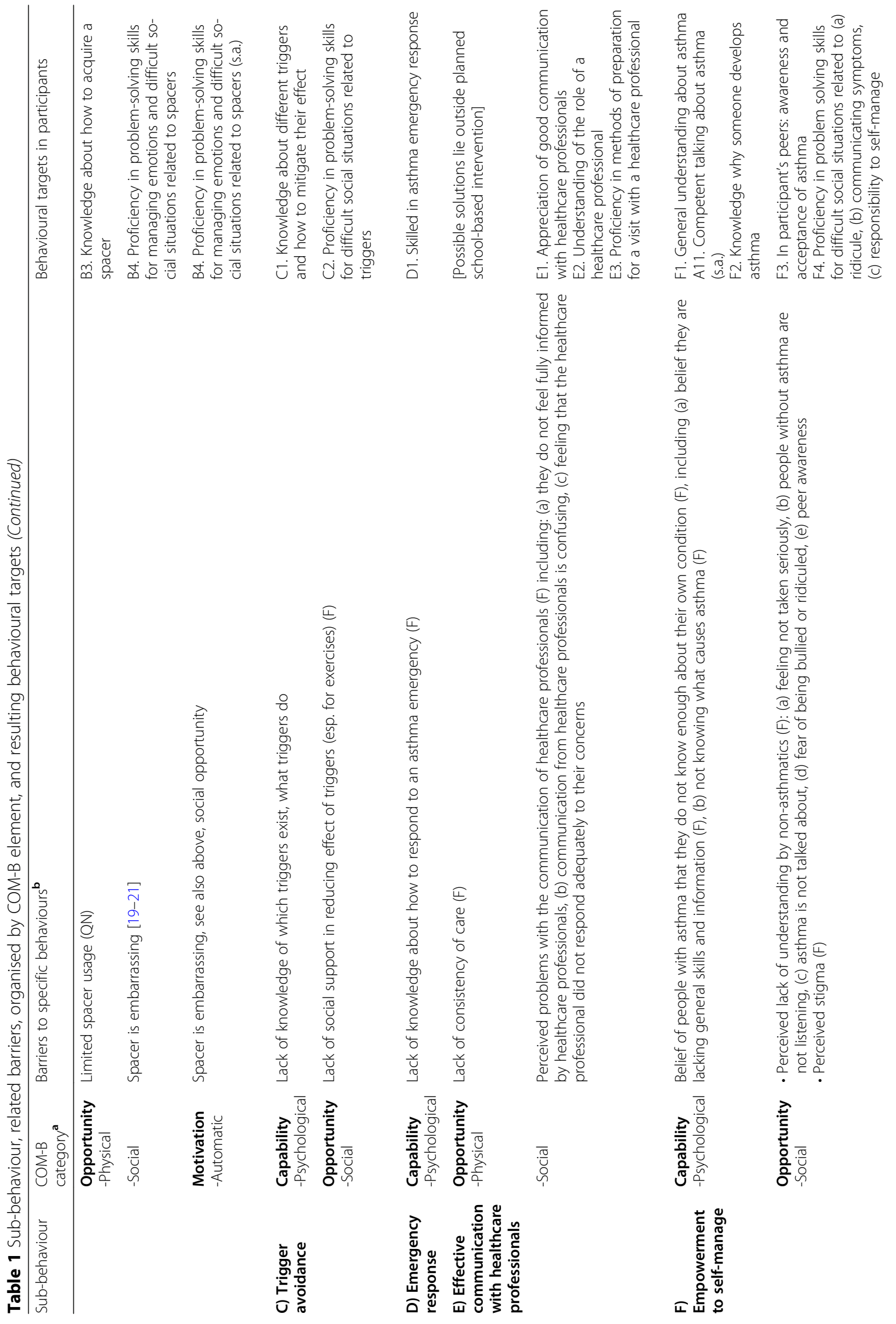




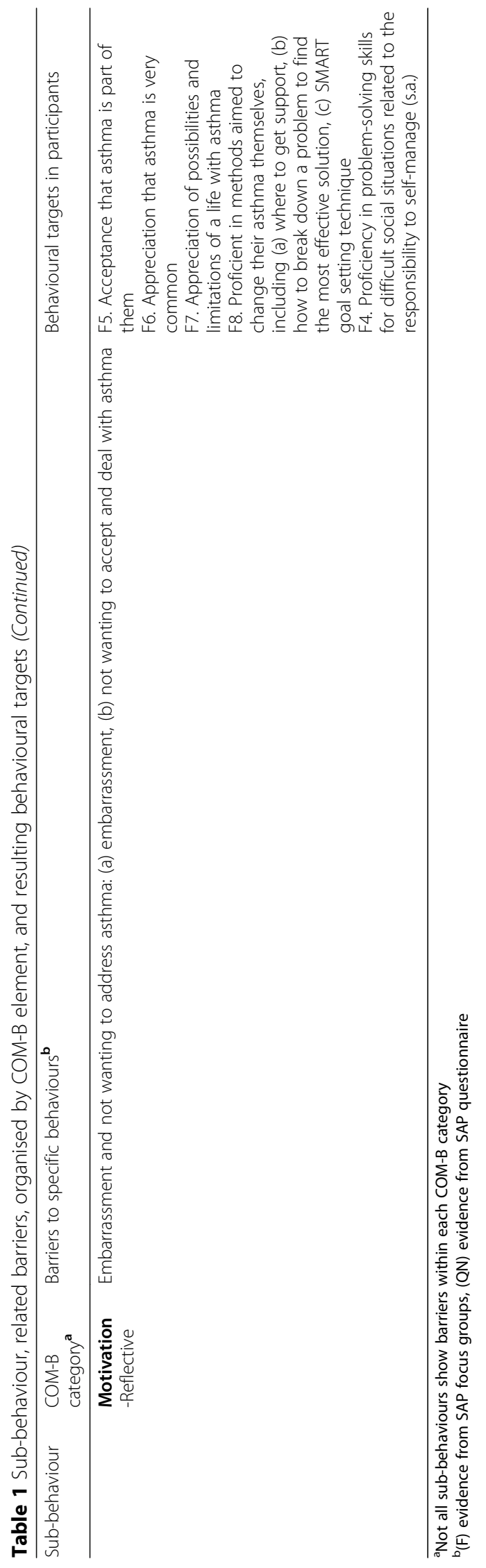


address identified behavioural targets within the intervention were regularly discussed between the outreach and learning team and the Centre of the Cell team of science communicators.

iii) Multidisciplinary experts from the fields of behaviour change, respiratory conditions, teaching, and paediatrics

iv) A National Institute for Health Research (NIHR) lay advisory panel, a group of lay people organised by the NIHR met with the research team and discussed various aspects of the project. Elements of the study were also presented to the public at interactive stalls during six science and community festivals, such as the annual QMUL festival of communities.

Workshop content was reviewed in regard to ageappropriate design and language, as well as theoretical appropriateness according to behaviour change theory. Ideas were then tested and refined.

Work on the 'In Control' theatre provocation was undertaken by GLYPT (Greenwich and Lewisham Young People's Theatre) Tramshed, who are experts of performance arts aimed at changing attitudes in adolescents and have in the past worked with young people about gang violence. The MAIS team collaborated with GLYPT on the development of the theatre workshop and organised training about the medical aspects of asthma for the theatre cast.

\section{Prototype intervention and categorisation of the intervention elements using BCTs Prototype intervention for testing}

The developed intervention involves two school visits (Table 2). The first visit is by the GLYPT theatre group, performing 'In Control' to the whole school year groups 7 and 8 (11 to 13 years of age) and addresses acceptance of asthma and understanding in both young people with asthma and their peers. Following a 40-min performance, there is a facilitated discussion with actors both in role then out of role, working through the main concepts of asthma acceptance within the characters and for the audience. During the second school visit, two members of the MAIS team facilitate four consecutive 1-h workshops to young people with asthma from year groups 7 and 8, with additional support from a member of the research team. During the scripted workshops, participants learn about asthma and the four asthma self-management sub-behaviours.

\section{BCT categorisation}

All agreed elements of the intervention were coded using the Behavioural Change Taxonomy (BCT) version 1 by Susan Michie [24]. The taxonomy lists 93 behavioural change techniques which are categorised into the following groups: (1) goals and planning, (2) feedback and monitoring, (3) social support, (4) shaping knowledge, (5) natural consequences, (6) comparison of behaviour, (7) associations, (8) repetition and substitution, (9) comparison and outcomes, (10) reward and threat, (11) regulation, (12) antecedents, (13) identity, (14) scheduled consequences, (15) self-belief, (16) covert learning. Two coders independently coded all intervention elements, and any discrepancies were resolved through discussion. Table 2 shows the draft intervention with each element coded for BCTs and standards to support self-management.

Elements of the workshop include a short movie around problem solving and goal setting, role play to learn about appropriate emergency response and a giant airway to demonstrate air flow and the effects of different medicines. An information booklet and toolbox are handed out at the end of the workshop day. Elements of the intervention are designed to function as standalone activities or be combined for a tailored approach and have therefore been coded for BCTs separately. One technique however relates to the whole intervention. This technique is 'credible source', referring to the trained professionals, who are organising and facilitating the intervention. The use of protagonists in media elements of the intervention meant that several BCTs were applied indirectly, through avatars. These indirect BCTs have been indicated in cursive in Table 2 .

In total, 29 intervention elements were separately coded, including single elements from the workshops and the toolbox. One hundred sixty-three behavioural change techniques (BCTs) were identified for the intervention, including 40 different BCTs (Fig. 2). In line with our objective to improve asthma selfmanagement skills, the BCT applied most frequently within the intervention was 4.1, 'Instruction on how to perform the behaviour' with sixteen applications and nine applications of 6.1, 'Demonstration of the behaviour' and 8.1, 'Behavioural practice/Rehearsal' with seven applications.

The number of BCTs applied within any element of the intervention was between 1 and 18, which reflects how many different approaches to behavioural change are included within the intervention. The highest number of different BCTs has been coded for two games: 'Asthma Dash' board game (workshop 2) with 18 BCTs, and 'Asthma Dodge', mobile app game (toolbox) with 17 BCTs. Both games encompass several sub-behaviours including avoiding triggers and adherence to medication. They both put a focus on the reinforcement of behavioural change through 5.2, 'salience of consequences'. Other BCTs that were coded for both elements include 7.1. 'prompts/cues', 


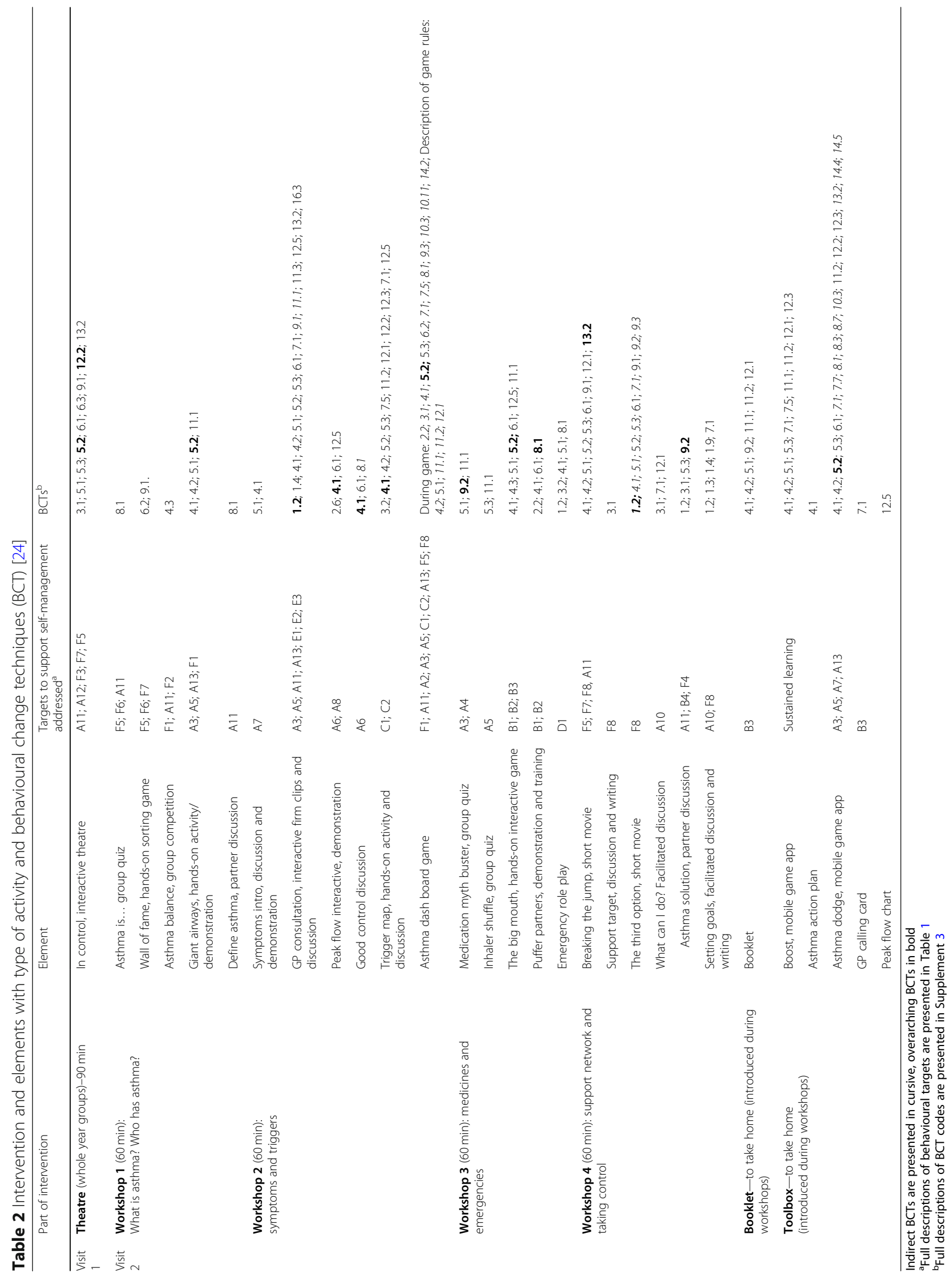




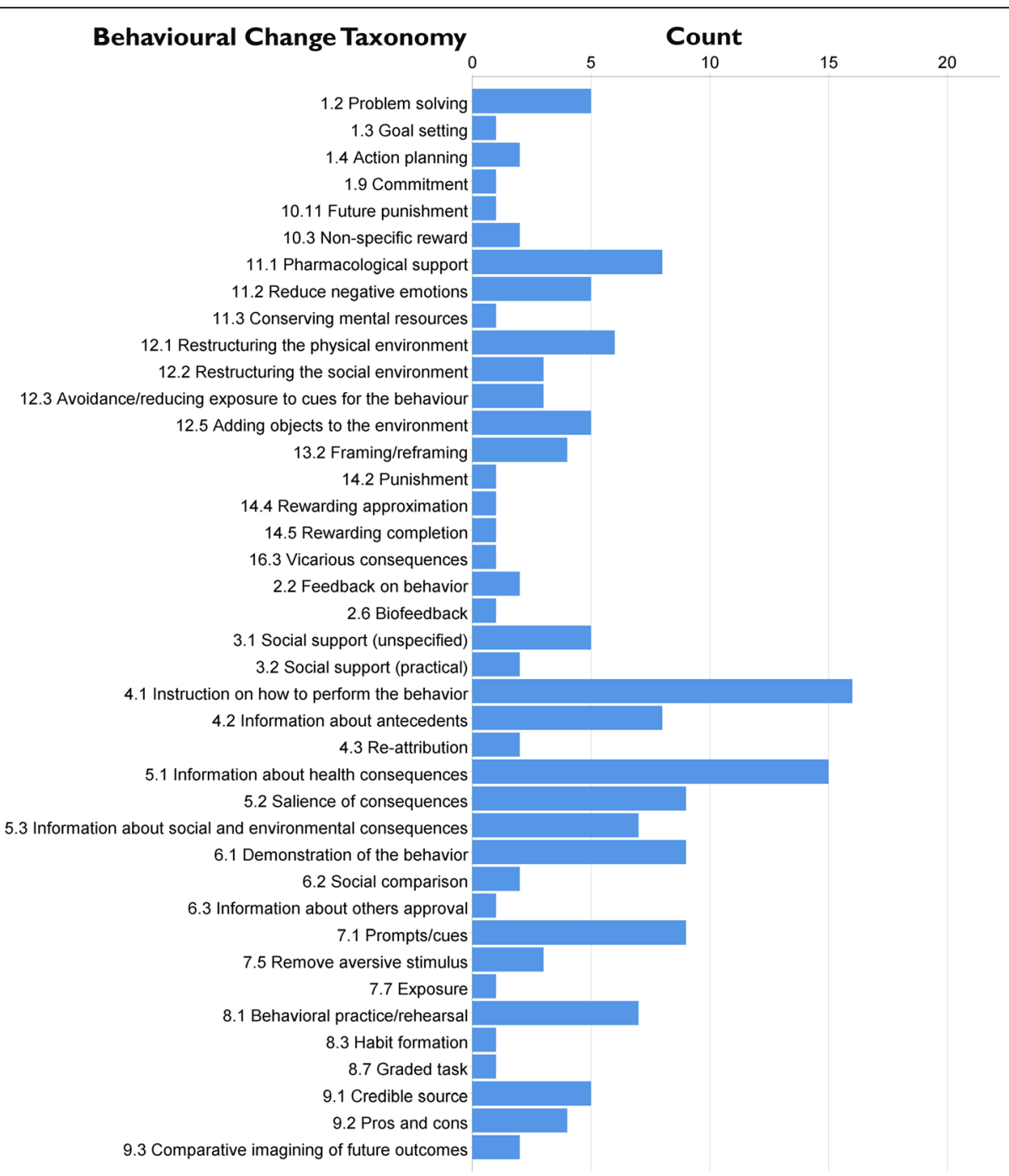

Fig. 2 Frequency of applied behavioural change techniques, according to the BCT taxonomy by S. Michie

8.1. 'behavioural practice/rehearsal', and 10.3. 'nonspecific reward'. Further details on the BCT coding are provided in Supplement 3.

\section{Feasibility phase}

The feasibility phase was conducted to:

- Test practicability and feasibility of delivering the intervention, especially within the school context;

- Understand acceptability of and participant's engagement with the intervention;

- Find out if the topic areas and elements addressed in the intervention had been understood;

- Gather general feedback about the intervention with a view to refinement.

\section{Design}

A pre-post study design to assess feasibility, acceptability and knowledge gained through both workshop and theatre visits.

\section{Recruitment of schools}

All schools who had previously worked with the study team on the school asthma project (between 2015 and 2018) or who had experience working with the GLYPT theatre company were invited to participate in the feasibility study $(n=50)$. Participants from London secondary schools who took part in the SAP were recruited from different year groups for the MAIS. If a school agreed to be part of the feasibility study and receive the theatre workshop, they were then offered the 1-day workshops 


\section{Inclusion criteria}

Theatre performance:

- Children aged 11-13

Asthma workshops:

Children with asthma as specified by the school asthma register

Children who had attended the theatre production

\section{Exclusion criteria}

Theatre performance:

Children younger than 11 or older than 13 .

Asthma workshops:

Any child not on the school asthma register

Any child who did not attend the theatre production

\section{Consent}

Theatre performance For the theatre performances, each school gave consent at a school management level. This form of gate keeper consent is common when interventions are delivered at a cluster level (i.e. in a school) and was considered appropriate, as the theatre does not identify individuals with asthma or discuss medical details about the condition, but focuses instead on perceptions around attitudes to health in all adolescents.

Workshops For the workshop visits, given previous experience that parental opt-in consent resulted in a drastic reduction of participants and given the low risk of the proposed intervention, parental opt-out consent and young people's assent were collected.

Procedures For economic reasons, the theatre part of the intervention was undertaken as a performance tour with all performances delivered by a team of young actors during three consecutive weeks. The workshop day was then offered to the schools who received the theatre performance for adolescents with asthma.

Evaluation Given the different recipients of the theatre visit (all young people) and the workshops visit (young people with asthma), the feasibility of these two school visits was assessed separately.

Feedback for the theatre performances was collected in a short questionnaire handed out and completed by the audience in a postcard-sized format directly after the end of the performance. The questionnaire included questions related to the enjoyment of the production itself, attitudes to asthma and attitudes to general health issues. There was room for free text comments about the performance.

The impact of the workshops on asthma knowledge was assessed using a previously developed questionnaire. Additional feedback questions after the workshops asked about acceptability and engagement. The research team also gathered evidence about practicability and general feasibility of the intervention.

\section{Results}

Feasibility phase results

Of the 50 schools invited to participate, nine schools agreed to receive the theatre performances. Twenty-two performances were arranged over a 3-week tour to ensure all 1814 young people in year groups 7 and 8 in these schools were targeted (mean 2.4 visits per school). The school visits for the theatre tour were arranged in a first step. Once the tour schedule was agreed, the research team then provided schools with the additional opportunity to participate in the workshops. Only one of these 9 schools accepted the additional offer of 1 day of asthma workshops. Given the low uptake of workshop visits, this two-step recruitment strategy was reviewed, as described in the 'Discussion' section.

\section{Theatre provocation}

Feedback forms on the theatre performance were filled out by all attending 1814 young people between 11 and 13 years of age. Feedback results are presented in Table 3.

The general feedback was very positive, and $91.3 \%$ of the audience said the theatre performance 'In Control' was very or completely enjoyable. $84.6 \%$ of the young people said that the performance also at least 'somewhat' changed how they think or feel about asthma. More specifically, more than $60 \%$ of the participants felt the performance made them want to help people with asthma (62\%), and the performance made them understand people with asthma better $(65.8 \%)$. The theatre provocation also had an impact on the participant's wider health perceptions. Over half of the young people (52.7\%) said the performance made them want to look after their own health better, and $53.9 \%$ said that the performance made them feel that people should talk more about health issues.

Examples of 155 free text comments from children with and without asthma included: 'I want to make people happy with asthma', 'Never laugh at people who have asthma (or any other healthy issues)', 'Should help my family with asthma', 'I wasn't comfortable with my asthma until now', and 'I think that I should bring in my asthma pump and tell a teacher'. 
Table 3 Feedback for the 'In Control' theatre as part of the intervention feasibility

\begin{tabular}{|c|c|c|c|c|}
\hline \multicolumn{5}{|c|}{ 1. How enjoyable was the performance? } \\
\hline Not at all & Hardly & Somewhat & Very & Completely \\
\hline $0.6 \%(11)$ & $0.7 \%(13)$ & $7.3 \%(131)$ & $38.5 \%(693)$ & $52.8 \%(950)$ \\
\hline \multicolumn{5}{|c|}{$\begin{array}{l}\text { 2. Did watching 'In Control' change how you think or feel about living } \\
\text { with asthma? }\end{array}$} \\
\hline Not at all & Hardly & Somewhat & Very & Completely \\
\hline $7.2 \%(129)$ & $8.2 \%(146)$ & $26.9 \%(480)$ & $33.3 \%(593)$ & $24.4 \%(434)$ \\
\hline \multicolumn{3}{|c|}{ 3. I want to help people with asthma } & \multicolumn{2}{|l|}{$62 \%(1122)$} \\
\hline \multicolumn{3}{|c|}{$\begin{array}{l}\text { 4. I feel I understand people with asthma } \\
\text { better }\end{array}$} & \multicolumn{2}{|l|}{$65.8 \%(1191)$} \\
\hline \multicolumn{3}{|c|}{ 5. My opinion about asthma has not changed } & \multicolumn{2}{|l|}{$12.6 \%(228)$} \\
\hline \multicolumn{3}{|c|}{$\begin{array}{l}\text { 6. I feel motivated to look after my own } \\
\text { health better }\end{array}$} & \multicolumn{2}{|l|}{$52.7 \%(953)$} \\
\hline \multicolumn{3}{|c|}{$\begin{array}{l}\text { 7. I feel people should talk about health } \\
\text { issues more }\end{array}$} & \multicolumn{2}{|l|}{$53.9 \%(975)$} \\
\hline
\end{tabular}

Numbers in brackets represent number of participants. For questions 3 to 7 , participants choosing 'Yes' as an answer are presented (options: Yes/No)

The feasibility of including the performance as part of the intervention was reviewed between actors, the MAIS team, and GLYPT Tramshed half-way through the theatre tour, as well as after the last performance. Feedback from the actors was that there should be a limit of about 90 children for each performance whenever possible. The performances had on average 83 students attending. A number of up to 90 children allow to have the audience seated in a full circle around the stage with seats only two rows deep. This seating arrangement makes it easier to engage with the audience, compared to a classic set up with a frontal stage and multiple rows.

\section{Workshops}

When the schools were asked if they would like to receive a day of asthma-related workshops in addition to the planned theatre visit, one of the nine schools agreed to accommodate the workshops. The asthma register of that school identified 23 pupils with asthma in years 7 and 8. All of these engaged and completed the workshops. Nineteen participants completed the questionnaire as shown in Table 4. Fifteen of the 19 participants agreed or strongly agreed that the workshops were fun or interesting. Seventeen out of 19 participants also said the workshops changed at least somewhat how they think or feel about asthma and what it means to live with it. When asked to give examples of what changed, answers included 'the fact that you always have to keep your inhaler with me, I didn't think that this was serious before', 'I learnt how to handle certain situations' and 'to understand how to use inhaler better'.

The change in number of participants who correctly answered knowledge questions about asthma pre and
Table 4 Feedback for the workshops as part of the intervention feasibility study

1. Did the workshops change how you think or feel about asthma and
what it means to live with it? $n=19$
$\begin{array}{lllll}\text { Not at all } & \text { Hardly } & \text { Somewhat } & \text { Very } & \text { Completely } \\ 1(5.3 \%) & 1(5.3 \%) & 6(31.6 \%) & 6(31.6 \%) & 5(26.3 \%)\end{array}$

2. Were the workshops fun or interesting? $n=18$

Strongly disagree Disagree Uncertain Agree Strongly agree $\begin{array}{lllll}0 & 1(5.3 \%) & 3(15.8 \%) & 8(42.1 \%) & 7(36.8 \%)\end{array}$

Numbers in brackets represent percent of participants

post workshops are presented in Table 5. Generally, asthma knowledge was quite poor before the workshops and improved after the workshop. Knowledge of why a spacer should be used was particularly low before the workshops, with only 4 participants giving the correct answer. The highest increase from 6 to 12 participants was recoded for the question why people develop asthma. All general knowledge areas were correctly answered by at least $66.7 \%$ of participants after the workshops.

Post workshop reflections from the team suggested that the workshops were feasible and acceptable both to students and teachers who all responded positively to being part of the study. It was perceived that a group of 23 in the workshop was too large to maintain the intended interactivity. After discussing possible group sizes with Centre of the Cell learning experts, a maximum number of 15 was agreed for future workshops. Workshops 2 and 3 ran for 75 min which was reported as too long. It was therefore decided to reduce the number of iterations of some included activities, as well as change two group work activities into briefer partner activities. The preparation and logistics of the workshop were considered feasible.

The overall set up of the intervention in two visits was also reviewed and was judged to be feasible.

\section{Discussion}

\section{Summary of findings}

The development of the MAIS intervention demonstrates the benefit of applying a systematic and theoretical approach to intervention development and allows a thorough translation of barriers to self-management of asthma into new behavioural targets.

Use of a behaviour change taxonomy to code intervention elements ensured that the most relevant techniques were used and resulted in a rich and varied approach to support behaviour change. The use of different entertainment media and gamification, with media-based or gamified elements, also resulted in an engaging intervention, which was well received. Both elements of the intervention resulted in very positive feedback from the 
Table 5 Before-after questionnaire to assess knowledge about asthma in the feasibility study

\begin{tabular}{|c|c|c|}
\hline Knowledge questions & Before, $n=19$ & After, $n=18$ \\
\hline General asthma knowledge & Correct before (\%) & Correct after (\%) \\
\hline How many young people have asthma & $9(42.3)$ & $14(73.7)$ \\
\hline There are ways to reduce the effect that asthma has on life & $11(52.4)$ & $15(75)$ \\
\hline Why do people develop asthma & $6(28.6)$ & $12(80)$ \\
\hline Common symptoms of asthma & $17(85)$ & $19(90.5)$ \\
\hline Asthma does not require treatment & $17(81)$ & $19(90.5)$ \\
\hline Inhalers do not work if you do not feel them working & $7(33.3)$ & $15(71.4)$ \\
\hline Spacers & Correct before (\%) & Correct after (\%) \\
\hline Why should a spacer be used & $4(20)$ & $14(66.7)$ \\
\hline Emergencies & Correct before (\%) & Correct after (\%) \\
\hline I know what to do when someone has an asthma attack & $9(56.3)$ & $17(94.4)$ \\
\hline When is emergency care needed & $6(42.9)$ & $12(70.6)$ \\
\hline Triggers & Median [mean] before & Median [mean] after \\
\hline Recognised triggers out of list of 10 & $6[6.3]$ & $10[8.7]$ \\
\hline Differences SABA and corticosteroid inhalers & Median [mean] before & Median [mean] after \\
\hline Correctly identified inhaler statements out of 6 & $2[1.6]$ & $4.5[3.9]$ \\
\hline
\end{tabular}

young people involved. $91.3 \%$ of the theatre audience said the performance 'In Control' was very or completely enjoyable, and $94.7 \%$ of workshop participants agreed the workshops were fun or interesting. Feedback by actors and the theatre company was positive. Running the theatre as a tour with all performances delivered by a team of young actors during three consecutive weeks worked well. Some small changes were undertaken to the intervention after the feasibility study, primarily in terms of workshop length, and implications for future trial procedures were apparent. Comments received from the actors about ideal audience size will furthermore inform future delivery.

The feasibility phase showed that the intervention content is acceptable and practicable in its proposed form, and that it has the potential to change attitudes and understanding towards asthma. Yet, it did highlight some issues with regards to the workshops. Primarily this related to the recruitment strategy, which offered the workshops to schools after they had been booked into the theatre tour. That meant teachers had already started to make arrangements for the theatre visit and would have needed to change plans in order to also accommodate the workshops. This additional commitment may have been a barrier to accepting the workshop visit. Future qualitative research will explore such barriers in more detail and consider changes to the recruitment strategy, for example by offering theatre and workshops elements together.

\section{Comparison to existing evidence}

While interactive media is becoming increasingly common in behavioural change interventions, the assessment of these approaches is still in its infancy. The approach of using interactive media in this study was built on some initial positive findings that indicate potential benefits of using media for psychosocial, behavioural change or symptom relief [25]. It is clear that using, for example, serious games or gamification in an intervention has a great potential to engage participants through a rich sensory experience. Furthermore, a driving factor for behavioural change, recognised across different theories, is motivation to change the behaviour. Games have proven to be a very effective way to improve the motivation for a behaviour [26]. The MAIS intervention development indicates that theatre, workshop media and gamified elements of an intervention can not only work through their motivation potential, but also have the capacity to build skills and social opportunity.

An interesting finding when developing the intervention was recognising a distinction between directly applied BCTs and an opportunity to allow for indirect approaches to behavioural change within media-based approaches. Games, films and theatres often use an avatar with which the player or audience identifies in order to carry and receive behavioural messages or to perform behaviours on their behalf. Currently it is not clear whether there is a differential effect of indirect and direct BCTs, but recognising the difference is an important step towards this. It may be hypothesised that applying a behavioural change technique indirectly can help to reach patients who may consider a more direct approach too intrusive or may not be ready to change. It should furthermore be noted that a larger number of BCTs may not be a direct reflection of how effective an element might be in improving self- 
management behaviour, rather the appropriateness of the $\mathrm{BCT}$ for the underlying aim may be more important.

\section{Strengths and limitations}

An important strength of the study is the robust development of the intervention. Having a feasibility phase in the real world also allowed for refinement of the intervention and alerted us to questions such as the best model of delivery, particularly of workshops. The inclusion of many different intervention elements, all using appropriately selected techniques to change behaviour, also has ensured the intervention is engaging.

There are however some limitations of the current study. In relation to the intervention, it mainly focuses on group work and leaves less time for a more personalised approach, although during the fourth part of the workshop young people identify their own social support network and use individual problem solving and goal setting techniques. The use of primarily group work is considered relevant given the importance of social opportunity to support self-management in young people with asthma; however, it remains to be seen whether greater tailoring or more individual work could be helpful. The main elements of the intervention are also delivered within a short time frame ( 2 days) rather than over a period of weeks, meaning practice of learnt skills within the intervention period is limited. This was decided in order to avoid dropout over time and make delivery more feasible within a school setting where disruption on multiple days may be difficult. Elements such as apps and information materials were provided to the young people when leaving the workshops however to foster a sustainable effect.

The objective of the current study was intervention development, and therefore at this stage effectiveness data both on clinical outcomes or process measures such as change in behaviour was not possible; however, this would be the objective of future studies given the current findings of acceptability and feasibility.

Similarly, the design of the feasibility assessment particularly of the theatre provocation relied only on postperformance questionnaires and therefore does not account for baseline attitudes or understanding and therefore cannot reflect the degree of change. Assessment of the workshops did however involve baseline assessments and hence could show change, although the lack of a previously validated tool is a limitation.

The recruitment strategy was also problematic with only one school receiving workshops, so results may not be representative for other schools. A pilot study which not only confirms intervention acceptability but examines trial procedures would therefore be helpful before a full effectiveness study.

\section{Conclusions}

The use of theory (including the MRC (Medical Research Council) guidelines for the development of a complex intervention and the COM-B model for behavioural change) together with expert and user input can lead to an acceptable and feasible intervention. This approach combined with an innovative and varied format including multimedia helped to ensure the intervention is interesting and engaging.

Consideration however should be given to how schools are offered both components of the intervention, i.e. theatre and workshop visits to the school to ensure uptake to both. Further evaluation is also needed on how the intervention can be delivered at scale.

The MAIS intervention will now be assessed with young people between 11 and 13 years of age in a pilot cluster randomised control trial (RCT) with a view to improvement in adherence behaviour, asthma control, quality of life and health care use.

\section{Supplementary information}

Supplementary information accompanies this paper at https://doi.org/10. 1186/s40814-020-00670-6.

Additional file 1:. Supplement 1: TiDieR Framework

Additional file 2:. Supplement 2: Logic model

Additional file 3:. Supplement 3: Elements of the intervention, behavioral targets related to them, as well as BCTs addressed by the element

\section{Abbreviations}

ACT: Asthma Control Test; BCT: Behavioural Change Technique (taxonomy); CLAHRC: Collaboration for Leadership in Applied Health Research and Care; COM-B: Capability, Opportunity, Motivation-Behaviour; GLYPT: Greenwich \& Lewisham Young People's Theatre; MAIS: My Asthma in School

(intervention); MRC: Medical Research Council; NIHR: National Institute for Health Research; QMUL: Queen Mary University of London; RCT: Randomised Control Trial; SAP: School-based Asthma Project; TIDieR: Template for

Intervention Description and Replication (checklist)

\section{Acknowledgements}

The research team is very grateful to the continued support from Centre of the Cell with the creation of engaging learning content, in particular to Professor Fran Balkwill and Katie Chambers. Thank you very much to Jeremy James and Tunde Euba from the Greenwich and Lewisham Young People's Theatre (GLYPT) Tramshed who collaborated with us to develop a strong theatre piece about asthma. A special thanks to Norrice Liu and Gary Foley for reviewing the content of the intervention from a medical perspective. The team would furthermore like to thank the staff at the paediatric respiratory clinics at the Royal London Hospital and the Whittington Hospital, as well as the CLAHRC lay advisory panel for their help with the involvement of young asthma sufferers with the study.

\section{Authors' contributions}

GM was the main author of this manuscript. She was responsible for the development of the intervention components and contributed to the planning of the My Asthma in School (MAIS) intervention. LS supervised GM's work on the manuscript, with a particular input and focus on elements related to behavioural change. She additionally acted as second coder for $\mathrm{BCT}$ s. $\mathrm{KH}$ contributed to the planning of the MAIS intervention together with GM and acted as reviewer for this manuscript. $\mathrm{KH}$ also obtained ethical approval for the observational SAP study and the pilot of the MAIS intervention, as well as prepared the MAIS pilot protocol. JG is the principal investigator for the My Asthma in School intervention study and provided 
overall direction and supervision during the intervention development. All authors read and approved the final manuscript.

\section{Funding}

This research was supported by the National Institute for Health Research (NIHR) Collaboration for Leadership in Applied Health Research and Care (CLAHR) North Thames at Bart's Health NHS Trust (NIHR CLAHRC North Thames). The views expressed in this article are those of the author(s) and not necessarily those of the NHS, the NIHR or the Department of Health and Social Care. The project was in addition supported by The Barts Charity. The funders had no direct involvement in the design of the study and collection, analysis and interpretation of data, or in writing the manuscript.

\section{Availability of data and materials}

The datasets used and/or analysed during the current study are available from the corresponding author on reasonable request.

\section{Ethics approval and consent to participate}

Ethical approval for this study has been given by Queen Mary Research Ethics Committee (reference number QMERC2017/77). Participant consent and assent has been collected in accordance with its ethical approval. A more detailed description of how consent was given can be found in the methods section of this manuscript.

\section{Consent for publication}

Not applicable.

\section{Competing interests}

The authors declare that they have no competing interests.

\section{Author details}

${ }^{1}$ Centre for Genomics and Child Health, Blizard Institute, Barts and the London School of Medicine and Dentistry, Queen Mary University of London, 4 Newark St, London E1 2AT, UK. ${ }^{2}$ Centre for Primary Care and Public Health, Barts and the London School of Medicine and Dentistry, 58 Turner St, London E1 2AB, UK

Received: 14 October 2019 Accepted: 19 August 2020

Published online: 02 September 2020

\section{References}

1. Global Initiative for Asthma. Pocket guide for asthma management and prevention: GINA executive summary. 2018:28. https://ginasthma.org/2018 pocket-guide-for-asthma-management-and-prevention/. Accessed $27 \mathrm{Sept}$ 2019.

2. Harris K, Mosler G, Williams SA, et al. Asthma control in London secondary school children. J Asthma. 2017:54(10):1033-40. https://doi.org/10.1080/ 02770903.2017.1299757.

3. Asthma UK. The UK National Review of Asthma Deaths (NRAD). 2014:19. https://www.asthma.org.uk/globalassets/campaigns/nrad-executivesummary.pdf. Accessed 27 Sept 2019

4. Wolfe I, Cass H, Thompson MJ, et al. Improving child health services in the UK: insights from Europe and their implications for the NHS reforms. BMJ. 2011;342:d1277. https://doi.org/10.1136/bmj.d1277.

5. Bitsko MJ, Everhart RS, Rubin BK. The adolescent with asthma. Paediat Respir Rev. 2014;15(2):146-53. https://doi.org/10.1016/j.prrv.2013.07.003.

6. Naimi DR, Freedman TG, Ginsburg KR, et al. Adolescents and asthma: why bother with our meds? J Allergy Clin Immunol. 2009;123(6):1335-41. https:// doi.org/10.1016/j.jaci.2009.02.022.

7. Michaud P-A, Suris JC, Viner R. The adolescent with a chronic condition: epidemiology, developmental issues and health care provision. In: WHO discussion papers on adolescence. Geneva; 2007:52. http://apps.who.int/iris/ handle/10665/43775.

8. Craig P, Dieppe P, Macintyre S et al. Developing and evaluating complex interventions: new guidance. Medical Research Council (MRC); 2006:39. www.mrc.ac.uk/complexinterventionsguidance.

9. Guevara JP, Wolf FM, Grum CM, et al. Effects of educational interventions for self management of asthma in children and adolescents: systematic review and meta-analysis. BMJ. 2003:326(7402):1308-9. https://doi.org/10.1136/bmj. 326.7402.1308.
10. Gerald LB, Wittich AR, Erwin S, et al. Outcomes for a comprehensive schoolbased asthma management program. J Sch Health. 2006;76(6):291-6. https://doi.org/10.1111/j.1746-1561.2006.00114.x.

11. Ahmad E, Grimes DE. The effects of self-management education for schoolage children on asthma morbidity: a systematic review. J Sch Nurs. 2011; 27(4):282-92. https://doi.org/10.1177/1059840511403003. Accessed 27 Sept 2019.

12. Harris KM, Kneale D, Lasserson TJ, et al. School-based self management interventions for asthma in children and adolescents: a mixed methods systematic review. Cochrane Database Syst Rev. 2015;4. https://doi.org/10. 1002/14651858.CD011651

13. Coffman JM, Cabana MD, Yelin EH. Do school-based asthma education programs improve self-management and health outcomes? Pediatrics. 2009; 124(2):729-42. https://doi.org/10.1542/peds.2008-2085

14. Michie S, van Stralen MM, West R. The behaviour change wheel: a new method for characterising and designing behaviour change interventions. Implement Sci. 2011;6(42). https://doi.org/10.1186/1748-5908-6-42.

15. Asthma UK, Manage your asthma. https://www.asthma.org.uk/advice/ manage-your-asthma/adults/ Accessed 7th Aug 2019.

16. Magzamen S, Patel B, Davis A, et al. Kickin' asthma: school-based asthma education in an urban community. J Sch Health. 2008;78(12):655-65. https:// doi.org/10.1111/j.1746-1561.2008.00362.x.

17. Christiansen SC, Martin SB, Schleicher NC, et al. Evaluation of a school-based asthma education program for inner-city children. J Allergy Clin Immunol. 1997;100(5):613-7. https://doi.org/10.1016/S0091-6749(97)70164-7.

18. Asthma UK, Using inhalers. https://www.asthma.org.uk/advice/inhalersmedicines-treatments/using-inhalers/ Accessed 7th Aug 2019

19. Crompton GK. How to achieve good compliance with inhaled asthma therapy. Respir Med. 2004;98(Supplement 2):35-40. https://doi.org/10.1016/j. rmed.2004.07.014

20. Bush A, Fleming L. Diagnosis and management of asthma in children. BMJ. 2015;350(h996). https://doi.org/10.1136/bmj.h996.

21. Howard S, Lang A, Sharples S, et al. See I told you I was taking it! - attitudes of adolescents with asthma towards a device monitoring their inhaler use: implications for future design. Appl Ergon. 2017;58:224-37. https://doi.org/ 10.1016/j.apergo.2016.06.018

22. Joronen K, Rankin SH, Sstedt-Kurki P. School-based drama interventions in health promotion for children and adolescents: systematic review. J Adv Nurs. 2008:63(2):116-31. https://doi.org/10.1111/j.1365-2648.2008.04634.x.

23. Balkwill F, Chambers K. Centre of the Cell: science comes to life. PLoS Biol. 2015;13(9):1-11. https://doi.org/10.1371/journal.pbio.1002240.

24. Michie S, Richardson M, Johnston $M$, et al. Behavior change technique taxonomy. Ann Behav Med. 2013;46(1):81-95. https://doi.org/10.1007/ s12160-013-9486-6.

25. Fleming TM, Bavin L, Stasiak K, et al. Serious games and gamification for mental health: current status and promising directions. Front Psychiatry. 2017;7:215. https://doi.org/10.3389/fpsyt.2016.00215.

26. Johnson D, Deterding S, Kuhn KA, et al. Gamification for health and wellbeing: a systematic review of the literature. Internet Interv. 2016;6:89106. https://doi.org/10.1016/j.invent.2016.10.002

\section{Publisher's Note}

Springer Nature remains neutral with regard to jurisdictional claims in published maps and institutional affiliations.

Ready to submit your research? Choose BMC and benefit from:

- fast, convenient online submission

- thorough peer review by experienced researchers in your field

- rapid publication on acceptance

- support for research data, including large and complex data types

- gold Open Access which fosters wider collaboration and increased citations

- maximum visibility for your research: over $100 \mathrm{M}$ website views per year

At BMC, research is always in progress.

Learn more biomedcentral.com/submissions 